\title{
Effect of Traffic Speed on Stresses and Strains in
} Asphalt Perpetual Pavement

\author{
Daba S. Gedafa ${ }^{1}$, Mustaque Hossain ${ }^{2}$ and Stefan A. Romanoschi ${ }^{3}$ \\ 1. Department of Civil Engineering, University of North Dakota, Grand Forks ND 58202-8115, USA \\ 2. Department of Civil Engineering, Kansas State University, Manhattan KS 66506, USA \\ 3. Department of Civil Engineering, University of Texas-Arlington, Arlington TX 76019-0308, USA
}

\begin{abstract}
Increasing traffic volumes and loads as well as public expectation for a long-lasting transportation infrastructure have necessitated designing perpetual pavements. The KDOT (Kansas Department of Transportation) conducted a field trial to investigate the suitability of perpetual pavement concept for Kansas highway pavements. The experiment involved construction of four thick pavement structures. To verify the approach of designing perpetual pavements on the basis of an endurance strain limit, the pavements were instrumented with gauges for measuring tensile strains at the bottom of asphalt base layers at various speeds. Pavements were also instrumented with pressure cells to measure stress on the top of subgrade. Pavement response measurements under known vehicle load were performed in August 2006. FWD (Falling-weight deflectometer) was also used to collect deflection data at $15 \mathrm{~m}$ intervals on the same date. FWD first-sensor (center) deflections were normalized and corrected to $20{ }^{\circ} \mathrm{C}$ temperature based on measured mid-depth pavement temperature. The result shows that strain and stress measurements show significant amount of variations. Measurements in the thickest section are the most consistent. The higher the traffic speed, the lower the strains and stresses. The difference between strains and stresses at $30 \mathrm{~km} / \mathrm{hr}$ and $65 \mathrm{~km} / \mathrm{hr}$ is higher than the difference between $65 \mathrm{~km} / \mathrm{hr}$ and 95 $\mathrm{km} / \mathrm{hr}$. This shows the effect of speed on stresses and strains decreases as the speed increases. Softer binder in the asphalt base layer results in lower strains, which confirms that softer binder results in higher fatigue life.
\end{abstract}

Key words: Traffic speed, stress, strain, perpetual pavement, deflection.

\section{Introduction}

The increasing traffic volumes and loads as well as the public expectation for a longer-lasting transportation infrastructure have necessitated designing flexible pavements with a life of up to 50 years. Perpetual pavements are expected to meet the need for such a longer-lasting pavement. Thick and stiff pavement layers in perpetual pavements reduce the strains and stresses at the bottom of the asphalt concrete layer, thereby reducing the potential for cracking to be initiated at the bottom [1].

Fatigue cracks may develop in the surface layer and propagate horizontally in the top lift. Because they

Corresponding author: Daba S. Gedafa, Ph.D., P.E., assistant professor, research fields: mechanistic-empirical design, pavement management system, non-destructive testing, materials engineering, and traffic engineering. E-mail: daba.gedafa@engr.und.edu. appear at the pavement surface, top-down cracks can be observed, and action can be taken to eliminate them. Asphalt overlays or inlays are the most common solutions currently applied for top-down cracks. The cracks that initiate at the surface are not eliminated through the perpetual pavement concept. The concept leads to pavement structures that crack only at the surface and need repair only at the surface. This failure mode leads to significant monetary savings for the repair, rehabilitation, and reconstruction of these pavements [2].

The KDOT (Kansas Department of Transportation) conducted a field trial to investigate the suitability of perpetual pavement concept for Kansas highway pavements. The experiment involved construction of four perpetual pavement sections. To verify the approach of designing perpetual pavements on the basis of an endurance strain limit (70 micro-strains at 
the bottom of asphalt layer), the four pavements were instrumented with gauges for measuring tensile strains at the bottom of the asphalt base layers. Pavements were also instrumented with pressure cells to measure stresses on the top of subgrade. Pavement response measurements under known vehicle load and FWD (falling-weight deflectometer) were also performed [2].

\section{Objectives}

The main objective of the study was to investigate the effect of traffic speed on stresses and strains in perpetual pavement sections. Relationship between the FWD first-sensor (center) deflection and measured responses were also investigated.

\section{Test Sections}

Test sections in this study are the perpetual asphalt pavement sections on US highway 75 (US-75). The experiment involved construction of four thick pavement structures on a new alignment of US-75 near Sabetha, Kansas. To verify the approach of designing perpetual pavements based on an endurance strain limit, four pavements were instrumented with gauges for measuring strain at the bottom of the asphalt base layers. A research team from Kansas State University placed instrumentation systems in the four pavement structures during their construction in June 2005. Table 1 shows the pavement structures. The estimated design cumulative traffic for these pavements is 2.6 million ESALS/lane for 10 years and 5.7 million ESALS/lane for 20 years [2].

The KAPA (Kansas Asphalt Pavement Association) provided the design of Sections 1, 2, and 3. Section 4 was designed by KDOT. Sections 1 and 3 have the same thickness, but a softer binder (performance grade (PG 64-22)) SM (superpave mix) was used in the construction of the base asphalt mix instead of PG 70-22, and a richer and more ductile asphalt mix was used in the bottom lift of the base layer for Section 3. It is expected this mix will have a longer fatigue life.

The test sections were constructed on a fill and each was approximately $390 \mathrm{~m}$ long with approximately $150 \mathrm{~m}$ transition zones between them. The asphalt paving work was done in June 2005. The project was completed and the experimental sections were opened to traffic at the beginning of November 2005 [3].

\section{Data Collection}

\subsection{Stress and Strain Data}

Stress and strain data have been collected on four perpetual pavement sections. Each test section has multiple gauges, with half of the sensors located in the right wheel path (outer lane), and the other half located $150 \mathrm{~mm}$ to the right. Pavement response measurements were performed under $80 \mathrm{kN}$ standard truck load. On each pavement section, three sets of five passes of the loading truck were performed. Five passes were performed with the truck passing at about $30 \mathrm{~km} / \mathrm{hr}$, $65 \mathrm{~km} / \mathrm{hr}$, and $95 \mathrm{~km} / \mathrm{hr}$, in order to determine the effect of vehicle speed on pavement responses.

Horizontal strains and the vertical stress on top of subgrade as well as the position of the loading truck

Table 1 Configuration of test sections.

\begin{tabular}{|c|c|c|c|c|}
\hline Section & 1 & 2 & 3 & 4 \\
\hline Acronym & KAPA (Standard) & High reliability & KAPA 2 (Modified) & KDOT \\
\hline Surface course & 40 mm, SM 9.5A (PG 70-28) & & & \\
\hline Binder course & 60 mm, SM 19 A (PG 70-28) & & & \\
\hline Base course & 225 mm, SM 19A (PG 70-22) & $\begin{array}{l}175 \text { mm, SM } 19 \text { A } \\
\text { (PG 64-22) }\end{array}$ & $\begin{array}{l}\text { 225, SM } 19 \text { A } \\
(\text { PG 64-22) }\end{array}$ & $\begin{array}{l}300 \text { mm, SM 19A } \\
\text { (PG 64-22) }\end{array}$ \\
\hline Stabilized subgrade & $150 \mathrm{~mm}, 6 \%$ hydrated lime mix & ed with the natural soil & & \\
\hline Natural subgrade & High plasticity clay (A-7-6) & & & \\
\hline
\end{tabular}


were recorded with a national instruments data acquisition system at a rate of 300 records per second. A sampling rate of $3,000 \mathrm{~Hz}$ was used and the average value for ten samples were recorded. The data were recorded in text format in separate files for each passes of the vehicle and were then processed using Microsoft excel [2].

\subsection{FWD Deflection Data}

FWD (falling-weight deflection) deflection data used in this study were collected with a Dynatest 8000 FWD. The tests were done at $15 \mathrm{~m}$ intervals.

\subsection{Pavement Mid-depth Temperature}

Pavement mid-depth temperature was measured on test sections during data collection session. The thermocouple of a temperature gauge was lowered into the holes drilled in the AC (asphalt concrete) layers and filled with oil to measure the temperature at the mid-depth of each AC layer at the time of response measurements [2]. Measured mid-depth temperature was used to correct normalized FWD first-sensor (center) deflection data to a standard temperature of $20{ }^{\circ} \mathrm{C}$.

\section{Data Analysis}

Structural capacities of flexible pavements are determined from surface deflection measurements. Currently the most widely used NDT (nondestructive testing) system is the FWD (falling-weight deflectometer) [4]. Measured deflections by FWD must be corrected to a standard load, usually $40 \mathrm{kN}$ [5] and to a predefined environmental condition. The most critical environmental factor affecting deflections in flexible pavements is the temperature of the AC layer [6-8]. Thus pavement deflection data must be adjusted to a reference temperature [9]. A two-step correction procedure typically needs to be applied. The first step consists of measuring the effective temperature of the AC layer, and the second step consists of adjusting the surface deflection to a reference temperature using a correction factor [10].

Normalized FWD center deflection data were corrected to a standard temperature of $20{ }^{\circ} \mathrm{C}$ based on measured mid-depth temperature. It should be noted that stress and strain measurements were not made at exactly the same location as the FWD deflection data.

\section{Results and Discussion}

\subsection{Longitudinal Strain}

Fig. 1 shows the effect of traffic speed on the longitudinal strain. In general, the higher the FWD center deflection, the higher the longitudinal strain at the bottom of the asphalt layer. The higher the traffic speed, the lower the longitudinal strain. Some of the gauges were removed during construction and later retrofitted in Section 3. That may be one of the reasons why the trend in longitudinal strain in Section 3 is somewhat different.

Comparison of maximum and average longitudinal strain at various speeds is shown in Fig. 2. The minimum longitudinal strain was not included since it is zero for all sections at all speeds. The higher the traffic speed, the lower the longitudinal strain for all sections. Section 4 shows the lowest maximum longitudinal strain at all speeds, which may be due to its highest thickness. The lowest average longitudinal strain is observed in Section 3 at all speeds, which shows that Section 3 has higher fatigue life because of its softer base mix.

Table 2 shows the significant difference test results for longitudinal strain at $5 \%$ significance level. Longitudinal strain at $30 \mathrm{~km} / \mathrm{hr}$ is not significantly different from the longitudinal strain at $65 \mathrm{~km} / \mathrm{hr}$ in all sections except Section 4 whereas it is significantly different from the longitudinal strain at $95 \mathrm{~km} / \mathrm{hr}$ in all sections except Section 3. Longitudinal strain at 65 $\mathrm{km} / \mathrm{hr} \mathrm{mph}$ is significantly different from longitudinal strain at $95 \mathrm{~km} / \mathrm{hr}$ in three out of the four sections. 


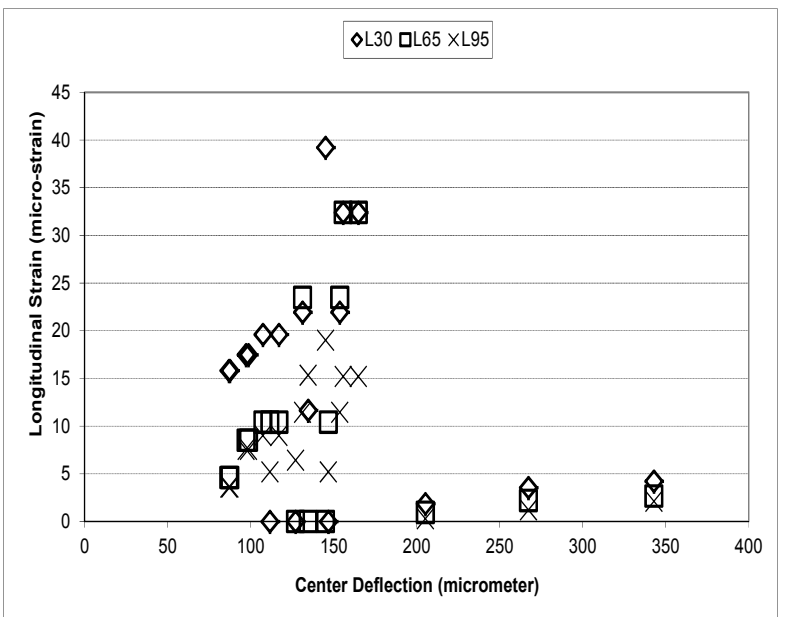

(a) Section 1

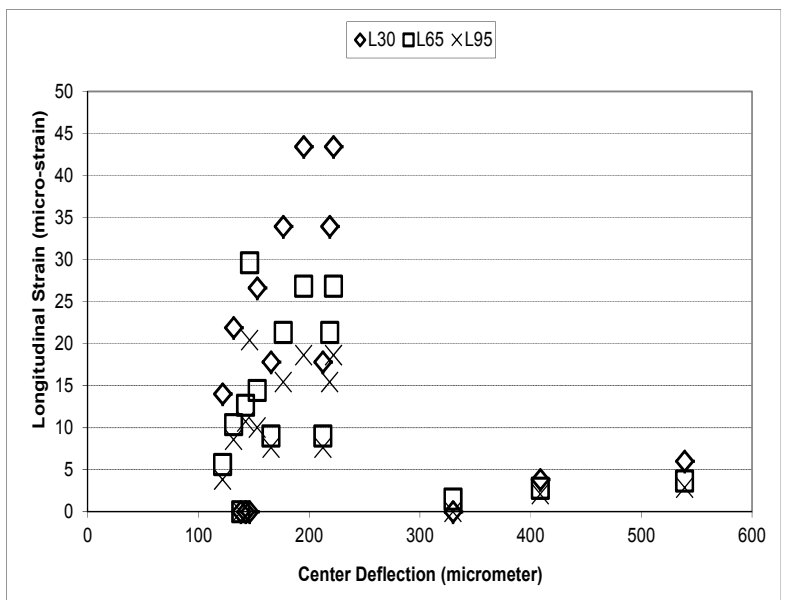

(c) Section 3

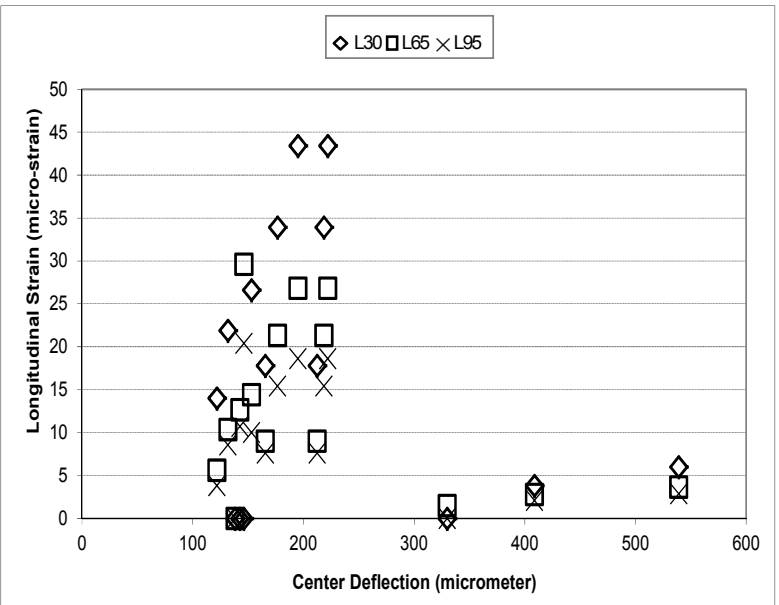

(b) Section 2

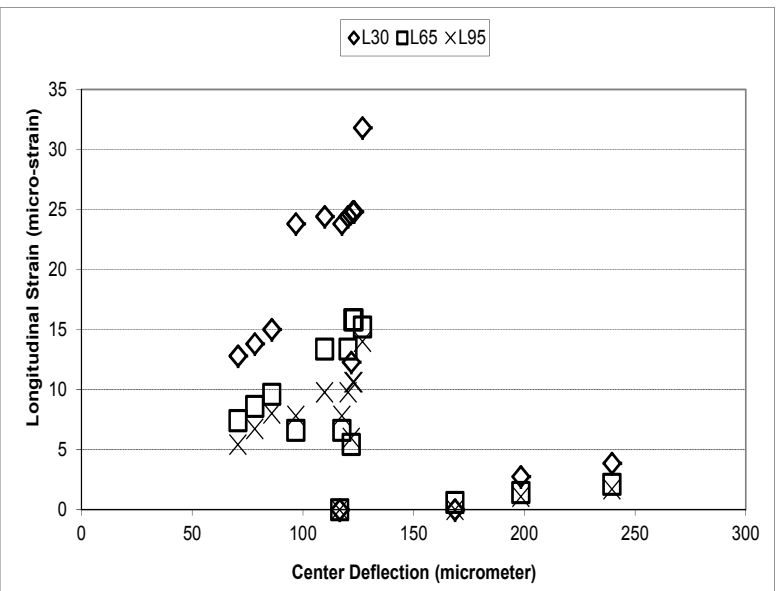

(d) Section 4

Fig. 1 Effect of traffic speed on longitudinal strain.

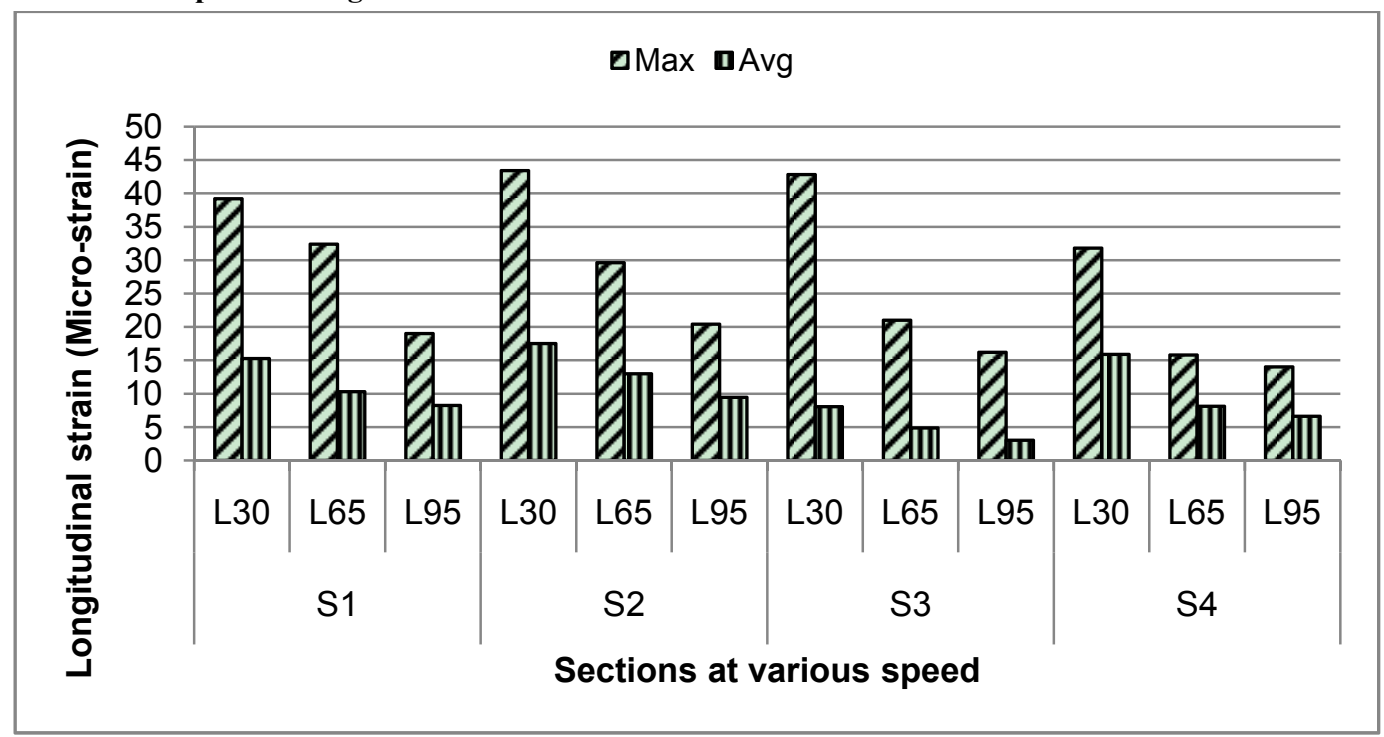

Fig. 2 Comparison of longitudinal strain at various speed, L30, L65, and L95 is longitudinal strain at $30 \mathrm{~km} / \mathrm{hr}, 65 \mathrm{~km} / \mathrm{hr}$, and $95 \mathrm{~km} / \mathrm{hr}$ speed, respectively. 
Table 2 Significant difference test for longitudinal strain.

\begin{tabular}{|c|c|c|c|c|c|}
\hline Sections & $\begin{array}{r}\text { Con } \\
\mathrm{g}\end{array}$ & $\begin{array}{l}\text { nparison } \\
\text { group }\end{array}$ & $\begin{array}{l}\text { Probability } \\
(P \text {-value })\end{array}$ & Similar & $\begin{array}{l}\text { Number of } \\
\text { data points }\end{array}$ \\
\hline \multirow{3}{*}{ S1 } & \multirow{2}{*}{ L30 } & L65 & 0.0708 & Yes & \multirow{3}{*}{18} \\
\hline & & L95 & 0.0022 & No & \\
\hline & L65 & L95 & 0.3655 & Yes & \\
\hline \multirow{3}{*}{ S2 } & \multirow{2}{*}{ L30 } & L65 & 0.1761 & Yes & \multirow{9}{*}{15} \\
\hline & & L95 & 0.0274 & No & \\
\hline & L65 & L95 & 0.0006 & No & \\
\hline \multirow{3}{*}{ S3 } & \multirow{2}{*}{ L30 } & L65 & 0.2592 & Yes & \\
\hline & & L95 & 0.1432 & Yes & \\
\hline & L65 & L95 & 0.0127 & No & \\
\hline \multirow{3}{*}{ S4 } & \multirow{2}{*}{ L30 } & L65 & 0.0002 & No & \\
\hline & & L95 & $<0.0001$ & No & \\
\hline & L65 & L95 & 0.0141 & No & \\
\hline
\end{tabular}

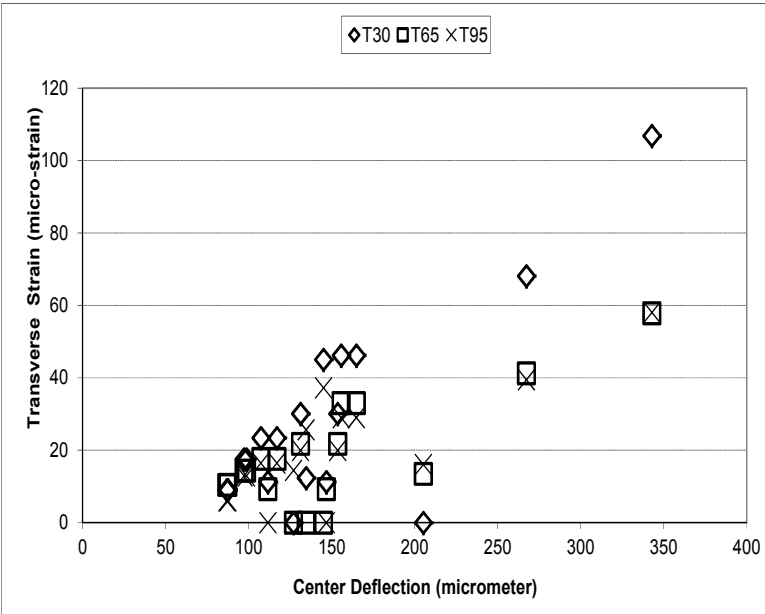

(a) Section 1

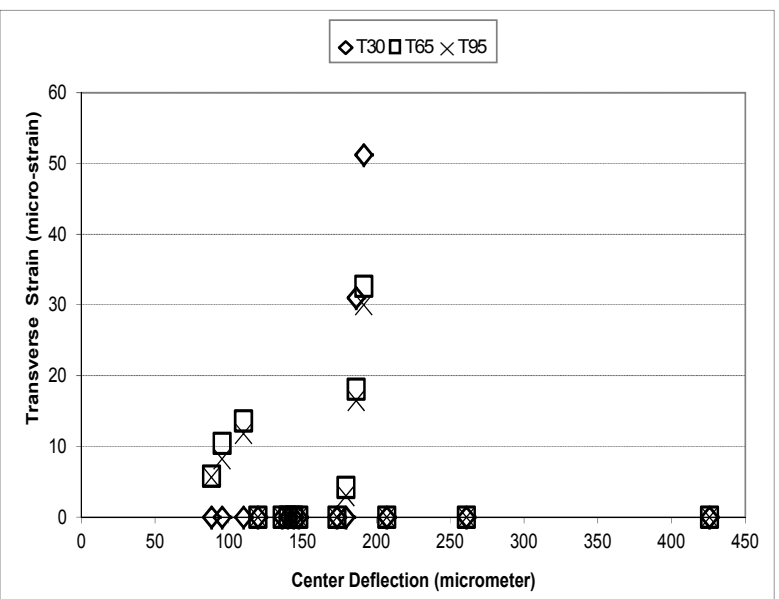

(c) Section 3

\subsection{Transverse Strain}

Fig. 3 shows the effect of traffic speed on transverse strains at the bottom of the asphalt concrete layer. It shows that the higher the center deflection, the higher the transverse strain. In general, the transverse strain also decreases with an increase in speed. Transverse strains at $65 \mathrm{~km} / \mathrm{hr}$ and $95 \mathrm{~km} / \mathrm{hr}$ are closer to each other than the transverse strains at $30 \mathrm{~km} / \mathrm{hr}$ and $65 \mathrm{~km} / \mathrm{hr}$. The trend is somewhat different in Section 3 as shown in Fig. 3c. This may be due to lower number of gauges since some were removed during construction and later retrofitted after construction.

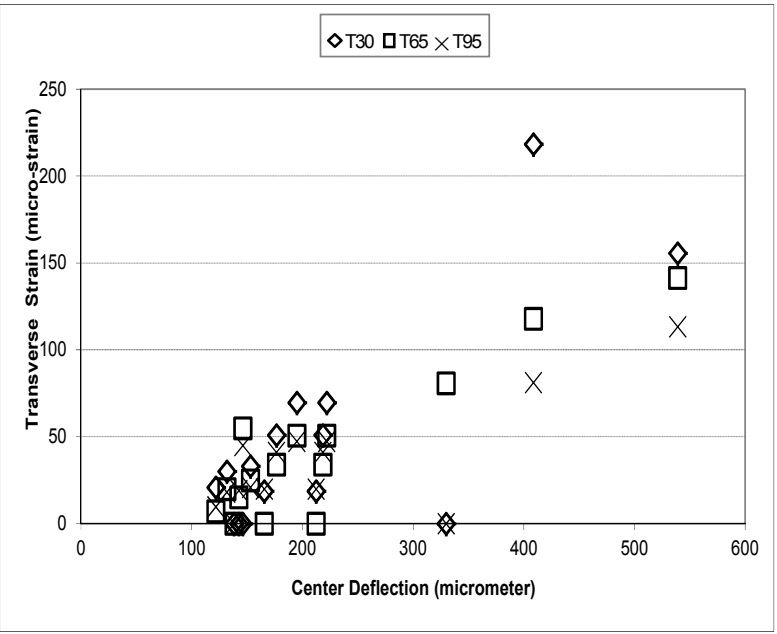

(b) Section 2

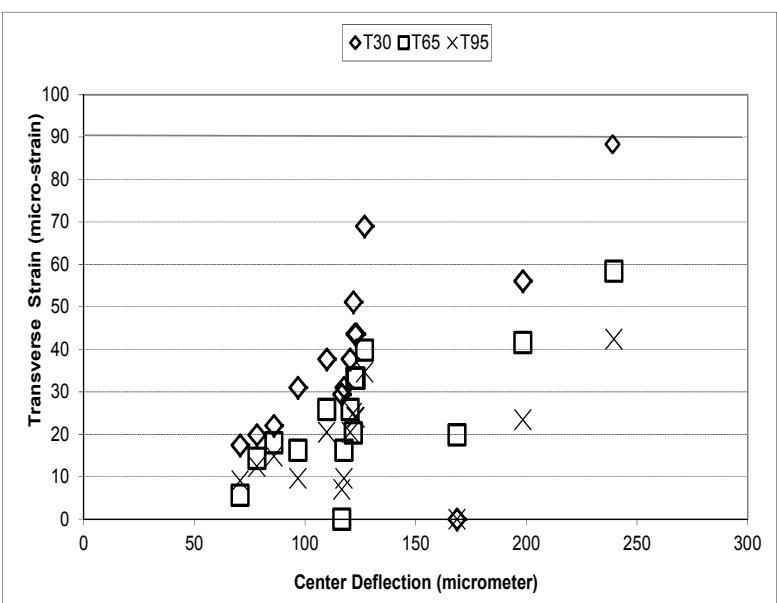

(d) Section 4

Fig. 3 Effect of traffic speed on transverse strain. 


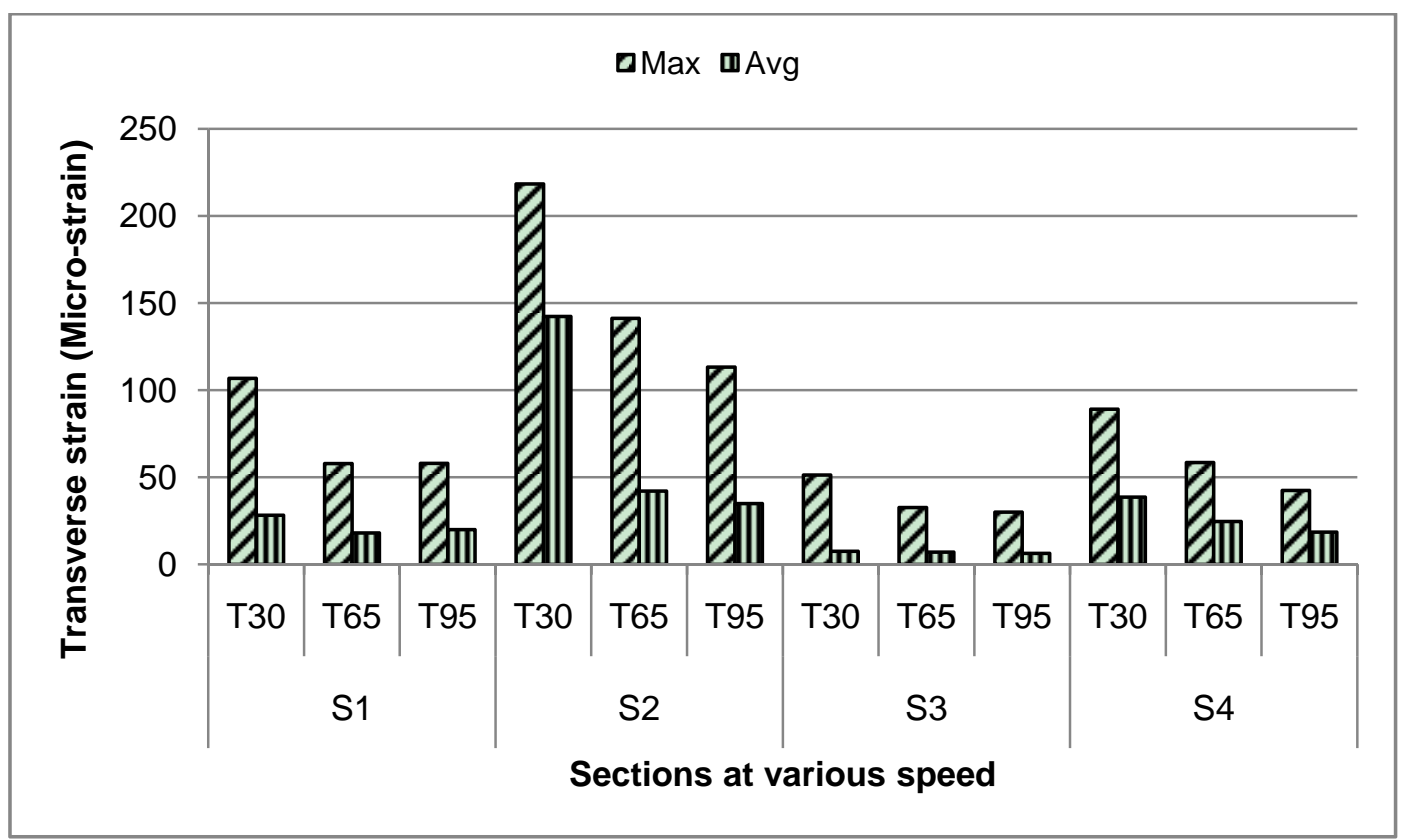

Fig. 4 Comparison of transverse strain at various speed, T30, T65, and T95 is transverse strain at $30 \mathrm{~km} / \mathrm{hr}, 65 \mathrm{~km} / \mathrm{hr}$, and $95 \mathrm{~km} / \mathrm{hr}$ speed, respectively.

Table 3 Significant difference test for transverse strain.

\begin{tabular}{|c|c|c|c|c|c|}
\hline Sections & Con & $\begin{array}{l}\text { parison } \\
\text { oup }\end{array}$ & $\begin{array}{l}\text { Probability } \\
(P \text {-value) }\end{array}$ & Similar & $\begin{array}{l}\text { Number of } \\
\text { data points }\end{array}$ \\
\hline \multirow{3}{*}{ S1 } & \multirow{2}{*}{ T30 } & T65 & 0.0144 & No & \multirow{3}{*}{18} \\
\hline & & T95 & 0.034 & No & \\
\hline & T65 & T95 & 0.5108 & Yes & \\
\hline \multirow{3}{*}{ S2 } & \multirow{2}{*}{ T30 } & T65 & 0.3056 & Yes & \multirow{9}{*}{15} \\
\hline & & T95 & 0.2808 & Yes & \\
\hline & T65 & T95 & 0.2896 & Yes & \\
\hline \multirow{3}{*}{ S3 } & Т30 & T65 & 0.7875 & Yes & \\
\hline & 150 & T95 & 0.6202 & Yes & \\
\hline & T65 & T95 & 0.0189 & No & \\
\hline \multirow{3}{*}{ S4 } & \multirow{2}{*}{ T30 } & T65 & 0.001 & No & \\
\hline & & T95 & $<0.0001$ & No & \\
\hline & T65 & T95 & 0.0092 & No & \\
\hline
\end{tabular}

Fig. 4 shows comparison of maximum and average transverse strains at various speeds. Minimum transverse strain was not included since it was zero in all sections. The higher the speed, the lower the transverse strain in all sections. The highest average and maximum longitudinal strain is observed on Section 2 since it is the thinnest section. The lowest average and maximum transverse strain is observed in Section 3. This confirms that softer binder in base layer results in lower strain.
Table 3 shows the significant difference test results for transverse strain. Transverse strain at $30 \mathrm{~km} / \mathrm{hr}$ is significantly different from the transverse strains at 65 $\mathrm{km} / \mathrm{hr}$ and $95 \mathrm{~km} / \mathrm{hr}$ in about half of the sections. Transverse strain at $65 \mathrm{~km} / \mathrm{hr}$ is significantly different from the one at $95 \mathrm{~km} / \mathrm{hr}$ in $50 \%$ of the sections.

\subsection{Stresses on Subgrade}

Fig. 5 shows the effect of traffic speed on the stresses on subgrade. Stress on the subgrade is mostly zero at lower center deflection in all sections except Section 3. The higher the traffic speed, the lower the stress (pressure) on subgrade. Stress on subgrade at 65 $\mathrm{km} / \mathrm{hr}$ and $95 \mathrm{~km} / \mathrm{hr}$ are closer to each other than stresses on subgrade at $30 \mathrm{~km} / \mathrm{hr}$ and $65 \mathrm{~km} / \mathrm{hr}$. There is a negative stress on subgrade in Section 1, which shows that it is tensile stress at that point.

Fig. 6 shows the comparison of minimum, maximum, and average stresses on subgrade at various speeds for all sections. Minimum stress on subgrade is zero in all sections except in Section 1 at $65 \mathrm{~km} / \mathrm{hr}$ and $95 \mathrm{~km} / \mathrm{hr}$ where it is negative. Negative minimum stress indicates a tensile stress. The highest 
maximum and average stress on subgrade are observed in Section 2 since it is the thinnest section.

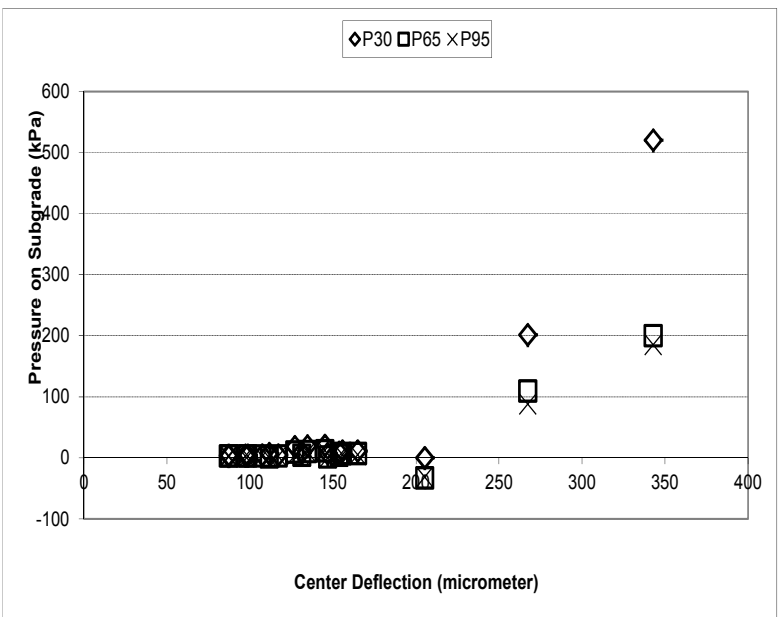

(a) Section 1

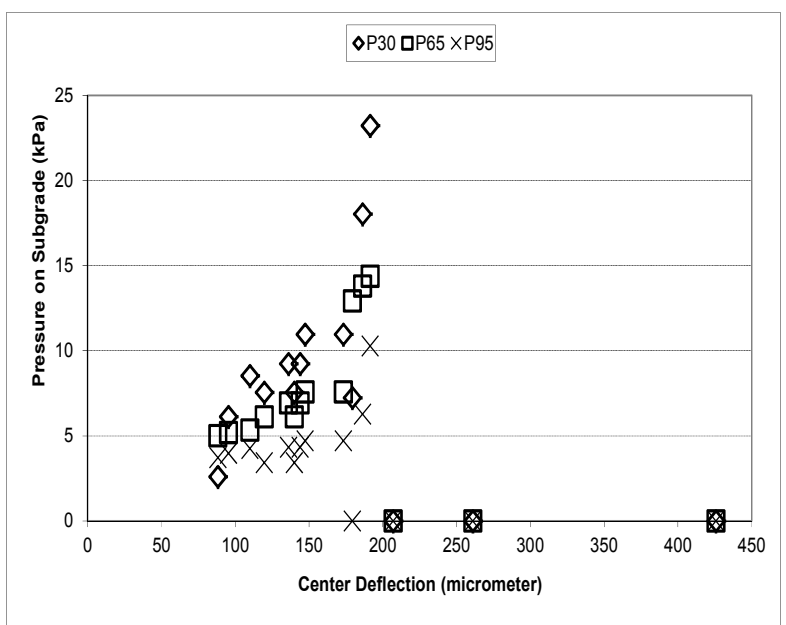

(c) Section 3
The lowest maximum and average stress on subgrade are observed in Section 3.

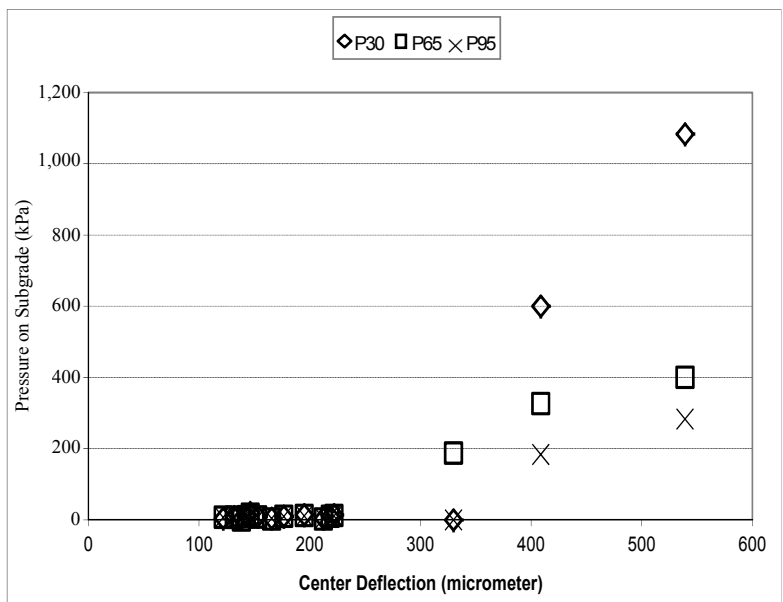

(b) Section 2

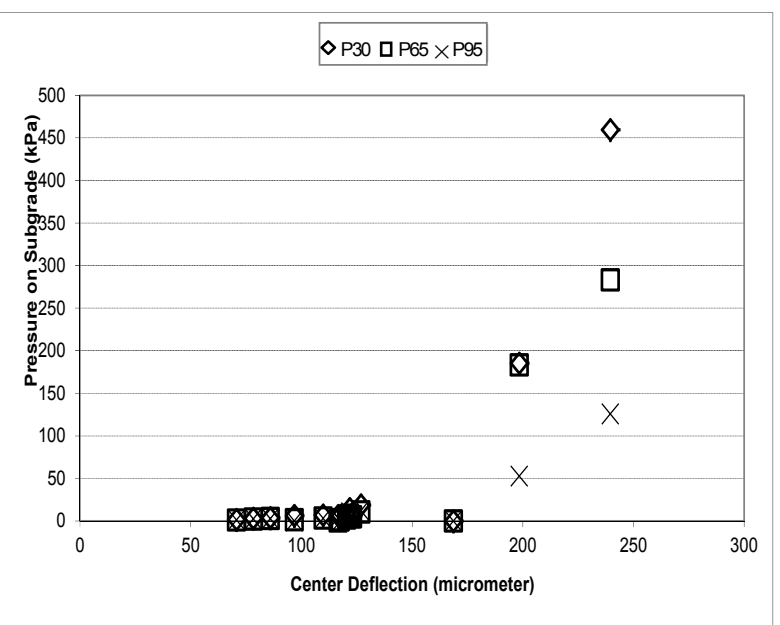

(d) Section 4

Fig. 5 Effect of traffic speed on stress on subgrade.

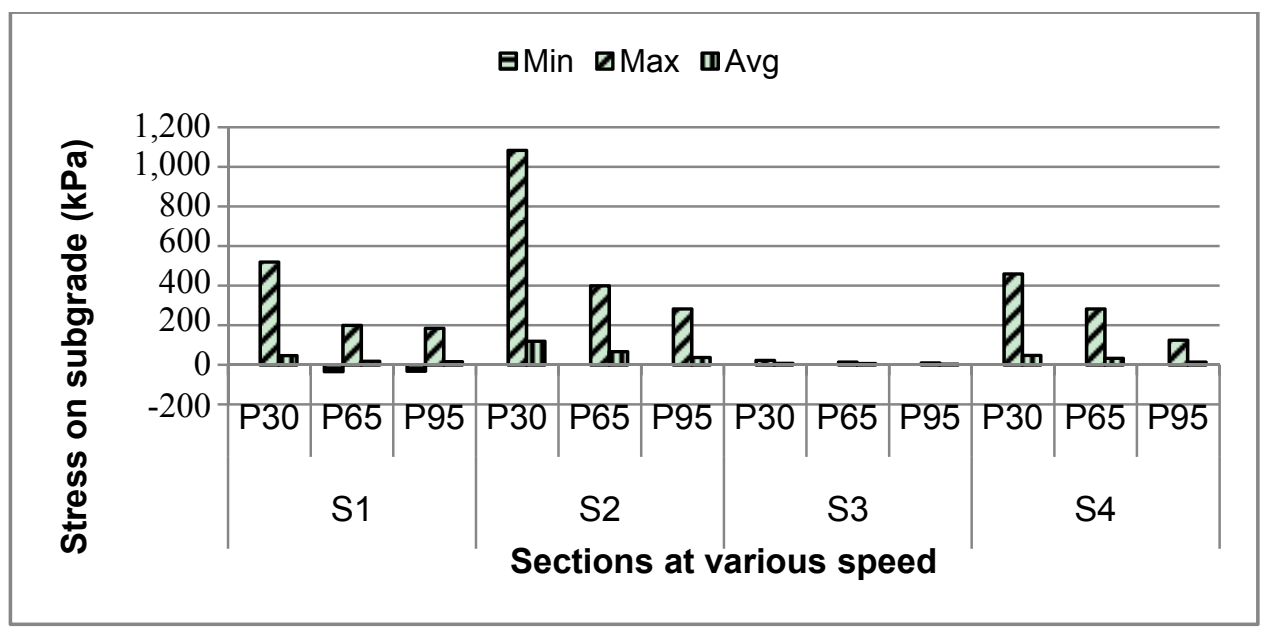

Fig. 6 Comparison of stress on subgrade at various speed, P30, P65, and P95 is pressure on the top of subgrade at $30 \mathrm{~km} / \mathrm{hr}$, $65 \mathrm{~km} / \mathrm{hr}$, and $95 \mathrm{~km} / \mathrm{hr}$ speed, respectively. 
Table 4 Significant difference test for stress on subgrade.

\begin{tabular}{|c|c|c|c|c|c|}
\hline Sections & Cor & $\begin{array}{l}\text { parison } \\
\text { oup }\end{array}$ & $\begin{array}{l}\text { Probability } \\
\text { ( } P \text {-value) }\end{array}$ & Similar & $\begin{array}{l}\text { Number of } \\
\text { data points }\end{array}$ \\
\hline \multirow{3}{*}{ S1 } & \multirow{2}{*}{ P20 } & $\mathrm{P} 40$ & 0.1334 & Yes & \multirow{3}{*}{-18} \\
\hline & & P60 & 0.1175 & Yes & \\
\hline & $\mathrm{P} 40$ & P60 & 0.0463 & No & \\
\hline \multirow{3}{*}{ S2 } & \multirow{2}{*}{ P20 } & P40 & 0.3134 & Yes & \multirow{9}{*}{15} \\
\hline & & P60 & 0.1775 & Yes & \\
\hline & $\mathrm{P} 40$ & P60 & 0.0887 & Yes & \\
\hline \multirow{3}{*}{ S3 } & \multirow{2}{*}{ P20 } & P40 & 0.0834 & Yes & \\
\hline & & P60 & 0.0006 & No & \\
\hline & $\mathrm{P} 40$ & P60 & 0.0037 & No & \\
\hline \multirow{3}{*}{ S4 } & \multirow{2}{*}{ P20 } & P40 & 0.2171 & Yes & \\
\hline & & P60 & 0.1628 & Yes & \\
\hline & P40 & P60 & 0.1698 & Yes & \\
\hline
\end{tabular}

Table 4 shows significant difference test results for stresses on subgrade at various speeds. There is no significant difference between the stresses on subgrade at $30 \mathrm{~km} / \mathrm{hr}$ and the other two speeds in all sections except the stress on subgrade at $95 \mathrm{~km} / \mathrm{hr}$ in Section 3. Stresses on subgrade at $65 \mathrm{~km} / \mathrm{hr}$ and 95 $\mathrm{km} / \mathrm{hr}$ are significantly different from each other in about half of the sections.

\section{Conclusions}

Based on this study, the following conclusions can be made:

- Strain and stress measurements show significant amount of variation. Measurements in the thickest section are the most consistent;

- The higher the traffic speed, the lower the strains and stresses in general. This confirms the viscoelastic nature of asphalt;

- The difference between strains and stresses at 30 $\mathrm{km} / \mathrm{hr}$ and $65 \mathrm{~km} / \mathrm{hr}$ is higher than the difference between $65 \mathrm{~km} / \mathrm{hr}$ and $95 \mathrm{~km} / \mathrm{hr}$ in general. This shows the effect of speed on strains and stress decreases as the speed increases;

- Softer binder in asphalt base layer results in lower strains, which confirms that softer binder results in higher fatigue life.

\section{Acknowledgments}

The authors would like to thank the Kansas Department of Transportation for sponsoring this study.

\section{References}

[1] Transportation Research Circular 503: Perpetual Bituminous Pavements, TRB (Transportation Research Board) of the National Academies, Washington, DC, 2001.

[2] S.A. Romanoschi, A.J. Gisi, M. Portillo, S. Dumitru, The first findings from the Kansas perpetual pavements experiment, Transportation Research Record: Journal of the Transportation Research Board 2068 (2008) 41-48.

[3] M.M. Portillo, Measured and theoretical response of perpetual pavement structures, Master Thesis, The University of Texas at Arlington, 2008.

[4] A. Loizos, G. Zachos, Investigation of the applicability of the L-FWD for flexible pavement layer materials, IJP-International Journal of Pavements 5 (1-3) (2006) 62-74.

[5] K. Chatti, S.W. Haider, H.S. Lee, Y. Ji, H. Salama, Evaluation of nonlinear and dynamic effects on asphalt pavement response under FWD loading, IJP-International Journal of Pavements 2 (1-2) (2003) 88-99.

[6] Y.R. Kim, Y.C. Lee, Interrelationships among stiffnesses of asphalt-aggregate mixtures, Journal of the Association of Asphalt Paving Technologies 64 (1995) 575-609.

[7] L. Shao, S.W. Park, Y.R. Kim, Simplified procedure for prediction of asphalt pavement subsurface temperatures based on heat transfer theories, Transportation Research Record: Journal of the Transportation Research Board 1568 (1997) 114-123.

[8] H.M. Park, Y.R. Kim, S. Park, Temperature correction of multiload-level, falling-weight deflectometer deflections, Transportation Research Record: Journal of the Transportation Research Board 1806 (2002) 3-8.

[9] D.H. Chen, J. Bilyeu, H.H. Lin, M. Murphy, Temperature correction on falling-weight deflectometer measurements, Transportation Research Record: Journal of the Transportation Research Board 1716 (2000) 30-39.

[10] D.Y. Park, N. Buch, K. Chatti, Effective layer temperature prediction model and temperature correction via falling-weight deflectometer deflections, Transportation Research Record: Journal of the Transportation Research Board 1764 (2001) 97-111. 